\title{
The factors influencing farmers' choice of improved maize seed varieties in Tanzania
}

\author{
Ange Pacifique Mutanyagwa ${ }^{1}$, Alida Isinika ${ }^{2}$ and Aloyce R. Kaliba ${ }^{3}$ \\ ${ }^{1}$ The Scientist in Rwanda Agriculture Board \\ ${ }^{2}$ Sokoine University of Agriculture \\ ${ }^{3}$ Professor of Economics and Co-Director University Center for Economic Development, College of \\ Business, Southern University and A\&M College
}

\begin{abstract}
The study examined the factors that influence farmers' choice of improved maize seed variety in Tanzania. Using purposive sampling data were collected from 930 households. The binary logistic regression model was used to choose respondent who had used improved maize seed from all seven agro-ecological zones of Mainland Tanzania. The results showed that agro-ecological zones, farm size, household size and yield positively influence the likelihood of farmers' choice of improved maize seed varieties. Based on these findings, it is recommended that researchers and suppliers of seed should consider the attributes of farmers' preference in the production of improved maize seeds and put more emphasis on facilitating the delivery of agricultural extension services for more effective uptake of agricultural technologies.
\end{abstract}

\section{Introduction}

Maize is the most important staple food in Tanzania, covering $80 \%$ of the population and it accounts for over $20 \%$ of agricultural GDP (URT, 2013). It's covers about $45 \%$ of the total cultivated area, generating about $50 \%$ of rural cash income and employment (USAID, 2010). It is estimated that the crop occupies the most important place among cereals with an annual per-capita consumption of 73 kilograms, contributing about $33 \%$ of the total household consumption (URT, 2013).

Improving maize production is therefore one of the most important strategies for food security in Tanzania, especially through the development and improvement of agricultural practices and availability of improved seed varieties (Hepelwa, 2013). However, improved seed varieties developed by the national and international agricultural research centres very often fail to get adopted by smallholder farmers (Morris et al., 1999), partly because farmers have different needs. They require maize seeds of diverse varieties and of multiple traits. This depends on crop variety traits or attributes, which are the performance characteristics of plant varieties that include both the production (agronomic) capacity of the plant and the consumption attributes of the product (Edmeades, 2003).

Most breeders of improved maize seed varieties have focused on raising yields, as well as addressing drought and disease tolerance. However, farmers perceive little advantage from such improvement because such seeds are not designed for their need (Reeves et al., 2002). It is, therefore, imperative to develop maize seed varieties which also accommodate attributes that are preferred by farmers. Improving maize breeding processes cannot be accomplished without the knowledge of attributes that farmers prefer in maize or any other variety. For effective breeding, farmers' preferences for varieties should be clearly identified through researcher-farmers interactions and collaboration (Banziger and Cooper, 2001).

Farmers' decisions are therefore not only driven by profit maximisation but rather by complex processes that are affected by several socio- 
economic and psychological variables (Willock et al., 1999).It has been estimated that smallholder farmers generally demand improved seed for three reasons namely; seed replacement, variety change and emergency response (Minot et al., 2007). Hence, seed demand is influenced by five types of factors including; (i) agro-ecological, natural and man-made disasters, (ii) uneven market

\section{Methodology}

A survey was conducted in the whole country of Tanzania mainland, where farmers who grow maize from all seven agro-ecological zones were selected to participate. Most farmers in these agroecological zones including the Lake zone, Northern zone, Eastern zone, Southern Highland zone, Southern zone, Western zone, and Central zone depended on rain availability. Farms size ranges from 0.5 to 75 ha which were located at altitude ranging from $0-1500 \mathrm{~m}$ above sea level with varied climatic condition.

The survey for the study was done in 2012/2013 by the Tanzania National Panel Survey, which was conducted through face to face interview focusing on maize production. Purposive sampling was employed in data collection to choose respondents who had used improved maize seed. The sample size of 930 households was selected from the National survey database for data analysis. The data were organized and coded for analysis using the Statistical Package for Social Science (SPSS) computer programme.

\section{Empirical model}

In order to determine factors that influence farmers' choice of the most preferred improved maize seed variety, a binary logistic regression model through maximum likelihood estimation procedures was used. The dependent variable used was farmers' choice of improved maize seed variety. The probability of farmers choosing certified maize seed was given the value of ' 1 ' while that of non-certified seeds was given the value of ' 0 '.

The model relates the probability to explanatory variable to the independent variables, such that the probability lies between 0 and 1 . The logistic cumulative probability function of the farmers who choose to use improved maize seed varieties is represented by equation (1) which is simplified:

$P_{i}=E\left[y=1 \mid x_{i}\right]=\frac{1}{1+e^{-z_{i}} \ldots \ldots . . .(1) ~}$ development, (iii) farmers' preferences about distribution channels, (iv) timing of seed distributions, and (v) the level of awareness about the traits of the improved seeds (Minot et al., 2007). However, the specific factors accounting for low seed adoption rates in Tanzania are not clearly articulated.

$$
\begin{aligned}
& P_{i}=\frac{1}{1-e^{-z_{i}}} \\
& P_{i}=\frac{1}{\frac{e^{z_{i}}+1}{e^{z_{i}}}}=1 \div \frac{e^{z_{i}}+1}{e^{z_{i}}} . \\
& P_{i}=1 \times \frac{e^{z_{i}}}{e^{z_{i}}+1} . \\
& P_{i}=\frac{1}{1+e^{-Z}}=\frac{e^{Z}}{1+e^{z}}
\end{aligned}
$$

Where;

$P_{i}=$ The probability of the $i^{\text {th }}$ farmer choosing to use the certified seed varieties; $P_{i}$ is nonlinearly related to the linear combination of multiple explanatory variables.

$\mathrm{e}=$ represents the base of natural logarithms.

If $P_{i}$ is the probability that the $i^{\text {th }}$ farmer choosing to use the improved seed varieties then, (1-P) represent the probability of farmers who do not choose to use improved maize seed varieties as given in equation (5)

$$
\begin{aligned}
& P_{i}=\frac{e^{z_{i}}}{e^{z_{i}}+1} \\
& 1-P_{i}=1-\frac{e^{z_{i}}}{e^{z_{i}}+1} \\
& 1-P_{i}=\frac{\left(e^{z_{i}}+1\right)-e^{z_{i}}}{e^{z_{i}}+1}=\frac{1}{e^{z_{i}}+1} \\
& 1-P_{i}=\frac{1}{1+e^{Z_{i}}}
\end{aligned}
$$

Dividing equation (5) by equation (9), the odds ratio in favour of farmers who choose to use improved maize seed variety is given as follows: 
$\frac{P_{i}}{1-P_{i}}=\frac{e^{z_{i}}}{1+e^{z_{i}}} \div \frac{1}{1+e^{z_{i}}}$

$\frac{P_{i}}{1-P_{i}}=\frac{e^{z_{i}}}{1+e^{z_{i}}} \times \frac{1+e^{z_{i}}}{1}=e^{z_{i}}$

$\frac{\mathrm{P}_{\mathrm{i}}}{1-\mathrm{P}_{\mathrm{i}}}$ (odds ratio) $=\frac{1-\mathrm{e}^{\mathrm{z}_{\mathrm{i}}}}{1-\mathrm{e}^{-\mathrm{z}_{\mathrm{i}}}}=e^{\mathrm{z}_{\mathrm{i}}} \ldots$

In order to estimate the Logit model, the dependent variable was transformed by taking the natural logarithm of equation 13 to obtain;

$L_{i}=\ln \left(\frac{P_{i}}{1-P_{i}}\right)=\ln e^{Z_{i}}=Z_{i}=\beta_{0}+\beta_{1} X_{1} \ldots+\beta_{11} X_{11}+\varepsilon \ldots(14)$

Where;

$\mathrm{L}_{\mathrm{i}}=\mathrm{Log}$ of odds ratio, $\mathbf{X}_{\mathbf{n}}=$ explanatory variables of the model, $\beta_{0}$ is the constant, $\beta_{1}$ for $i=1$ up to 15 are coefficients to be estimated and $\varepsilon=$ an error term.
The model which was used for empirical estimation is given in equation 15

$Y_{i}=\beta_{0}+\beta_{1} S+\beta_{2} M A R+\beta_{3} A G E+\beta_{4} E D U+\beta_{5} E X T+\beta_{6} H H S$

$+\beta_{7} F S+\beta_{8} D I S T+\beta_{9} Y L D+\beta_{10} D 2+\beta_{11} D 3+\beta_{12} D 4+$

$\beta_{13} D 5+\beta_{14} D 6+\beta_{15} D 7+\varepsilon_{i}$.

Where;

$Y_{i}=L_{i}=\log$ of odds ratio $\left(\frac{P_{i}}{1-P_{i}}\right)$ in relation to the use of improved maize seed varieties where 1 represent a farmer who used certified seed and zero for farmer who did not use certified seed

$\beta_{0}=$ Constant,$\quad \beta_{i}=$ Coefficients of explanatory variables estimated for $\mathrm{i}=1$ up to $\mathrm{i}=15$

$\varepsilon=$ An error term, $\mathbf{S}=$ Sex, $\mathbf{M A R}=$ Marital status, $\mathbf{A G E}=$ Age of the household head (years), $\mathbf{E X T}=$ Access to extension services, HHS=Household size, FS= Farm size, DIST=Distance to the market in $\mathrm{km}$, $\mathbf{Y L D}=$ Yield in $\mathrm{kg} / \mathrm{ha}, \mathbf{D}=$ Zones.

\section{III.Results And Discussion}

\section{Characterisation of Smallholder Farmers in All Agro-Ecological Zones in Tanzania}

The survey showed that more than half of the farmers had tertiary education (52.9\%) and these farmers were in their productive age being less than 45 years. Out of the above proportion, $39.8 \%$ were males and $13.1 \%$ were females. Furthermore, $28.7 \%$ had primary education and the rest had secondary education and this represents a very high literacy rate. Other sources of data however indicate that more than half of the population had attained primary education and very few have attained secondary or tertiary education. For example, the study conducted in Mbeya and Morogoro (Monela, 2014) demonstrated that majority of farmers $(61.5 \%)$ had attained primary education and only $1 \%$ had tertiary education.

However, when disaggregated by gender, it was found that male farmers were more educated than females at all levels of education. For example
$43.2 \%$ of the farmers with tertiary education were males compared to only $11.6 \%$ for females. This implies that smallholder maize production in Tanzania is dominated by farmers in their productive age, majority being men and literate, most having tertiary education. In relation to this study, a study conducted in Nigeria by Adeogun $e t$ $a l$.(2010) revealed that young farmers areenergetic and spends time in obtaining information on improved technologies. Similarly, Busari et al. (2015) found that younger farmers tend to be more innovative than older farmers. Furthermore, educated farmers are generally open to innovative ideas and new technologies as reported earlier by Weir and Knight (2000).

Moreover, smallholder farmers in Tanzania have social and economic characteristic that when fully utilized together with adequate and available 
extension services, maize production is more likely to increase significantly. In fact the readiness of maize farmers to use improved maize seed varieties increases due to the high level of literacy which make them open-minded when it comes to learning and implementing new techniques as noted earlier by Adeogun et al.(2010) and Busari et al. (2015).

Socio-economic characteristics of the respondents $(n=930)$

\begin{tabular}{|c|c|c|c|c|c|}
\hline Variable & Category & Frequency & Male (\%) & Female (\%) & Total (\%) \\
\hline \multirow[t]{2}{*}{ Sex } & Male & 695 & & & 74.7 \\
\hline & Female & 235 & & & 25.3 \\
\hline \multirow[t]{3}{*}{ Age } & $14-45$ & 492 & 39.8 & 13.1 & 52.9 \\
\hline & $46-60$ & 268 & 22.7 & 6.1 & 28.8 \\
\hline & $60+$ & 170 & 12.1 & 6.1 & 18.3 \\
\hline \multirow[t]{3}{*}{ Education } & Primary & 267 & 17.4 & 11.3 & 28.7 \\
\hline & Secondary & 153 & 13.1 & 3.4 & 16.5 \\
\hline & Tertiary & 510 & 43.2 & 11.6 & 54.8 \\
\hline \multirow[t]{4}{*}{ Marital status } & Single & 16 & 0.9 & 0.8 & 1.7 \\
\hline & Married & 771 & 70.5 & 12.5 & 83.0 \\
\hline & Divorced & 71 & 2.5 & 5.1 & 7.6 \\
\hline & Windowed & 72 & 0.8 & 6.9 & 7.7 \\
\hline Access to & Yes & 98 & 8.3 & 2.2 & 10.5 \\
\hline extension & No & 832 & 66.3 & 23.2 & 89.5 \\
\hline
\end{tabular}

Source: Author

Generally, smallholder maize farming in Tanzania is labour intensive and depends on household manpower or available labour such as spouse, children and relatives for various farm operations (e.g. land preparation, planting, weeding, and harvesting). This study revealed that $83 \%$ of the household heads are married and therefore their spouse, children and relatives provide family labour force which helps the farmer to reduce cost of outsourcing labour force for various farm activities. These findings are consistent with those of another study conducted by Leake and Adam (2015) who reported that households with high labour force readily adopt new technologies such as improved upland maize varieties than those with less labour force.

In relation to source of information or new technologies, this study revealed that only $10.5 \%$ of the farmers had access to extension services, whereby $8.3 \%$ were males and $2.2 \%$ females. Extension staffs form a major link between farmers and research institutes, centres, or breeders, helping farmers to adopt new innovations and improved farm management practices. However, the supply of extension services is low since only one out of ten farmers had access to extension staffs. This remains a stumbling block for farmers, limiting their ability to get information on new innovations.
In addition, the gender imbalance observed in accessing extension services seemed to push females far away from new innovations in all agro-ecological zones. This is however explained by the fact that women tend to spend extra hours after farm activities on various household chores and childcare. Meanwhile, men had more time to attend meetings, various social gathering, or even visiting extension staffs. Similar findings were reported by Omiti et al. (1999) who noted that constraints in accessing extension services leads to poor dissemination of new technologies to farmers. In addition, several studies has demonstrated the importance of extension services in adopting new technologies, increasing farmers' awareness to new technologies and its implementation (Paudel and Matsuoka, 2008; Tura et al., 2010; Umeh and Chukwu, 2013; Tiamiyu et al., 2014; Leake and Adam, 2015). Along the same lines, Kabanyoro et al. (2003) found that access to extension services significantly explains the farmer's willingness to adopt rice intercropping technologies.

Besides the fact that socio-economic characteristic of farmers do play an important role in the selection and adoption of agricultural technologies, the specific choice of a particular variety is highly influenced by the traits of seed variety. It is therefore equally important to give 
due consideration to such seed traits in crop breeding process.

\section{Factors Influencing Farmers' Choice of Improved Maize Seed Varieties}

The binary logistic regression model was used to determine the effects of socio-economic and agroecological zone on the smallholder farmers' choice of improved maize seeds varieties as presented in equation 15. Results from the binary logistic equation indicate that the variables influencing the use of improved maize seed varieties did contribute to the variation of the dependent variable between $17.1 \%$ and $22.9 \%$ as explained by Cox and Snell $\mathrm{R}$ square and Nagelkerke $\mathrm{R}$ square values. According to Tabachnick and Fidell (2001), the best goodness of fit for binary logistic regression model is indicated by " $p$ " values of the Omnibus tests and Hosmer and Lemeshow tests. For statistical significant probabilities of these tests should be less than 0.05 and greater than 0.05 respectively. Based on this, the model was statistically significant $(\mathrm{P}=0.0001)$ as shown by the Omnibus tests of model coefficients with a Chi square value of 174.027. Similarly, Hosmer and Lemeshow test indicates that the model represents good fit of the data as indicated by the Chi square value of 4.3 and significant level of $\mathrm{p}=0.829$ which is greater than 0.05. Results showed that the Wald statistics for all variables are non-zero values. According to Norusis (1990) and Powers and Xie (2000), the non-zero Wald statistic values indicate the presence of relationships between the dependent and explanatory variables. Thus, on the basis of the results of this study the null hypothesis was rejected in favour of the alternative hypothesis stating that socio-economic factors significantly influence the use of improved maize seed varieties at $5 \%$ level of significance.

\section{Factors influencing farmer's choice of improved maize seed varieties}

\begin{tabular}{|c|c|c|c|c|c|c|}
\hline Variables & B & S.E. & Wald & Df & Sig. & $\operatorname{Exp}(B)$ \\
\hline Sex & 0.144 & 0.171 & 0.708 & 1 & 0.400 & 1.155 \\
\hline Age & 0.005 & 0.005 & 1.273 & 1 & 0.259 & 1.005 \\
\hline Marital status & 0.018 & 0.161 & 0.013 & 1 & 0.910 & 0.982 \\
\hline Education level & 0.041 & 0.171 & 0.057 & 1 & 0.812 & 0.960 \\
\hline HH size & 0.052 & 0.027 & 3.762 & 1 & $0.050 * *$ & 0.950 \\
\hline Farm size & 0.434 & 0.196 & 4.926 & 1 & $0.026 * *$ & 0.648 \\
\hline Harvested yield & 0.001 & 0.001 & 5.253 & 1 & $0.022 * *$ & 1.000 \\
\hline Distance to market & -0.001 & 0.166 & 0.384 & 1 & 0.535 & 0.902 \\
\hline Access to ext. & 0.103 & 0.258 & 1.970 & 1 & 0.160 & 0.697 \\
\hline \multicolumn{7}{|l|}{ ZONE } \\
\hline Lake & 1.373 & 0.318 & 18.638 & 1 & $0.000 * * *$ & 3.946 \\
\hline Northern & 2.492 & 0.380 & 43.109 & 1 & $0.000 * * *$ & 12.086 \\
\hline Eastern & -0.835 & 0.358 & 5.453 & 1 & $0.020 * *$ & 2.305 \\
\hline Southern Highland & 1.125 & 0.364 & 9.547 & 1 & $0.002 * *$ & 3.081 \\
\hline Southern & 0.545 & 0.368 & 2.191 & 1 & 0.139 & 0.580 \\
\hline Western & 19.556 & 40187.631 & 0.000 & 1 & 1.000 & 0.000 \\
\hline Constant & 16.015 & 40187.631 & 0.000 & 1 & 1.000 & 9024713.411 \\
\hline Cox and Snell $\mathrm{R}^{2}$ & $17.1 \%$ & & & & & \\
\hline Nagelkerke $\mathrm{R}^{2}$ & $22.9 \%$ & & & & & \\
\hline $\mathrm{X}^{2}$ & coefficient & df & $\mathrm{p}$-value & & & \\
\hline Omnibus test of model & 174.027 & 16 & 0.000 & & & \\
\hline $\begin{array}{l}\text { Hosmer and Lemshow } \\
\text { test }\end{array}$ & 4.300 & 8 & 0.829 & & & \\
\hline
\end{tabular}


Note: $\mathrm{p} \leq 0.05 * *$

$\mathrm{p} \leq 0.01 * * *$

Dependent variable: choice of seed either certified or non-certified

Based on the model presented above, it was found that among ten variables tested only four variables contributed significantly. The variables

contributed significantly included household size, farm size, maize yield and agro-ecological zones, and these are discussed. Household size.

Household size has a positive and significant influence $(\mathrm{p}=.050 * *)$ on the choice of improved maize variety. An increase in household labour tends to increase the level of using improved maize seed varieties. For each additional family member in the household, there is an increase of 5 $\%$ more likely to use improved maize seed varieties, holding other variables constant. This suggests that a large family size provides more labour for farm operation and an increased incentive to produce more farm output at the same time cutting the cost of hiring labour from outside. Household size was used as a proxy for labour availability in the family and it may influence income earnings as well as expenditure. As Conteh et al. (2015) pointed out farming in most rural areas in developing countries depends on human labour, hence household size influences diversification in farming activities as multiple activities within the household requires more labour. Moreover, thefindings of this study conform to those obtained by Feder et al. (1985) in a study about adoption of agricultural innovations in developing countries. Feder, established that family size positively influenced adoption of agriculture innovations because of labour requirements for various farm activities. For that matter, an increase in household size creates an opportunity of increasing farm size due to labour availability as previous indicated by Wilson and Lewis (2015).

\section{a. Farm size}

The coefficient for farm size was positive at 0.434 , being significantly different from zero ( $p$ $=0.026$ ). This implies that a farmer who has a large farm size is more likely to use improved maize seed varieties compared to those with small pieces of land for crop production because farmers with large farms size seeks for profit. Farmers who own large pieces of land can afford to be more experimental because for them even a relatively small percentage of their total land may be large enough to support land-intensive technology. Land size could influence the use of improved maize seed varieties as farmer may portion a certain part of land for testing the newly certified improved seed varieties compared to people with small land sizes. Similarly, Simtowe et al. (2012) reported that farm size influenced adoption of various improved agricultural technologies, as observed earlier that the adoption or uptake of an innovation such as the use of improved maize seeds, fertilizer use, disease control and many more in farming enterprise tend to increase crop yield per unit area. Hence, with an increase in farm size there is a possibility of an increase in maize yield per unit increase of the crop area. It never ends there, but also this improves farm productivity and farmers' wellbeing.

\section{b. Harvested yield}

Yield is an important factor that can influence the use of improved maize seed variety among farmers. The results showed that harvested yield positively and significantly influenced the likelihood of farmers using improved maize seeds varieties $(p=0.022)$. These findings confirm the hypothesis that potential yield expectation for a particular variety positively influences the choice of improved maize seeds varieties. The results further suggest that smallholder farmers have incentive to purchase certified seeds using the money obtained from sales of maize from the previous harvest as Langyintuo and Mungoma, (2008) and Wen-chi et al. (2015) demonstrated earlier that the maize yield is positively correlated with adoption of new technologies.

The findings are also similar to those reported by Mbugua (2009) who conducted a study in Makuyu Division, Murang'a South District- Kenya, establishing that technology profitability in terms of high yields was significant in influencing adoption decision for using improved maize seed varieties. Nevertheless, different varieties of maize crop may show variations in crop yields in various agro-ecological zones, regardless of the fact that 
some maize varieties like SC 627 and SC 713 are recommended for a wide range of agro-ecological zones. It is therefore imperative for farmers of a particular zone to choose and use varieties recommended for their respective agro-ecological zones. It is therefore worth saying that, from this study the yield potential of a particular maize seed variety plays a crucial role in influencing farmers' preference of a particular maize seed variety.

\section{c. Agro-ecological zone}

The binary logistic regression model results showed that out of seven agro-ecological zones, three zones had a statistical significant probability of the farmer choosing the six most preferred improved maize seed variety. These are Lake $(\beta=$ $1.373, \mathrm{p}<0.001)$, Northern $(\beta=2.492, \mathrm{p}<0.001)$ and Southern Highland $(\beta=1.125, p<0.002)$. The Eastern zone $(\beta=-0.835, p<0.020)$ was less likely to adopt the six most preferred improved maize

\section{Conclusion And Recommendations}

The study shows that majority of the households head were married, therefore the spouse, children and relatives increased the manpower required for various farm activities. Whenever farmers have enough manpower they tend to look on possibility of increasing their farm size so that they can increase production. Although over fifty percent of the farmers had tertiary education, only 10 percent had access to extension services. Therefore, farmers are deprived of the right to agricultural information and their capacity for adoption of new innovations so that they increase farm production and productivity. The results of the binary logistic regression model showed that among the socioeconomic characteristics and others factors of the farmers that were found to influence the farmers' choice of improved maize varieties were household size, farm size, and harvested yield as well as some of the agro-ecological zones. Moreover, agro-ecological zone had a positive

\section{References}

[1] Adeogun, S.O., Olawoye, J.E. and Akinbile, L.A. (2010). Information sources to cocoa farmers on cocoa rehabilitation techniques (CRTs) in selected states of Nigeria. Journal Media and Communication Studies 2 (1): 009-015. [http://academicjournals.org/article/article1 seed varieties as compared to other zones. The implication of this finding is that agro-ecological zone influences the use of the six most preferred improved maize seed varieties, although in the Eastern zone there was a negative influence compared to the Central zone, which is used as the base.In fact the agro-ecological zones have different characteristics in terms of climate and soils qualities hence they are likely to support different types of maize seed varieties which is reflected in the farmers' uptake of the innovation within each zone. As such, the difference in farmers'preference for improved maize seed varieties in zones was statistically significant.

These findings are consistent with reports from Nigeria and Nepal by Fadare et al. (2014) in Nigeria and Kafne (2010) which demonstrated that agro-ecological zone was a major determinants of the rate at which farmers use improved maize seed varieties.

significance influence on the use of improved maize seed varieties, and the variation in the use of the improved maize seed varieties across agroecological zones was significant. The policy implication from this study is that in their effort to develop new improved maize seed varieties, breeders should focus their maize breeding efforts in those agro-ecological zones that perform best such as Lake, Southern Highlands and Northern zones while other crops that are well adapted to the other zones and are preferred by farmers in the other zones receive more research attention to breed for farmer-preferred traits for those crops as well for ensuring food security across the nation. Second, farmer's choice for improved maize seed variety was determined by potential yield among other criteria. Therefore it is imperative for breeders to consider farmers views, accommodating their preference, and needs when developing maize seed varieties.
380093281_Adeogun $\% 20$ et $\% 20$ al.pdf]
site visited on 05/09/2016.

[2] Banziger, M. and Cooper, M. (2001). Breeding for low input conditions and consequences for participatory plant breeding: examples from tropical maize and wheat. Euphytica 122: 503-519. 
[3] Busari, A.O., Idris-AdeniyiKaothar, M.I.A. and Olufunmi, P.A. (2015). Adoption of improved farming practices among arable crop farmers in Iwo Zone of Osun State Agricultural Development Programme. Journal of Agricultural Economics, Extension and Rural Development 2 (1): 240-243.

[4] Edmeades, S. (2003). Variety attributes and attribute trade-offs within the framework of Agricultural household models: The case of bananas in Uganda. $\mathrm{PhD}$ Dissertation, North Carolina State University. 133 pp.

[5] Feder, G., Just, R.E. and Zilberman, D. (1985). Adoption of Agricultural Innovations in Developing Countries. A survey. The University of Chicago. Economic Development and Cultural Change33: 255-298.

[6] Hepelwa, A., Selejio, O. and Mduma, J. (2013). The Voucher System and the Agricultural Production in Tanzania: Is the model adopted effective? Evidence from the Panel Data analysis. Enviroment for Development 5 (21): 1-24.

[7] Kafne. B. (2010). Determinants of adoption of Improved maize varieties in developing countries: A review. International Research Journal of Applied and Basic Sciences. Vol., 1 (1): 1-7, 2010.

[8] Langyintuo, A. and Mekuria, M. (2008). Assessing the influence of neighbourhood effects on the adoption of improved agricultural technologies in developing agriculture. African Journal of Agricultural and Resource Economics 2 (2): $151-169$.

[9] Mbugua, F. (2009). An analysis of factors influencing adoption of the recommended maize technology's package in Makuyu Division, Murang'a South District, Kenya. A Thesis for Award degree of Master of Arts of Kenyatta University. 113 pp.
[10] Minot, N., Smale, M., Eicher, C., Jayne, T., Kling, J., Horna, D. and Myers, R. (2007). Seed development programs in Sub-Saharan Africa: A review Mbugua of experiences. Prepared for the Rockefeller Foundation. Washington, D.C.: International Food Policy Research Institute.

[11] Montalto, C. P. and Gerner, J. L. (1998). The effect of expected changes in marital status on labour supply decisions of women and men. Journal of Divorce and Remarriage 28 (3/4): 25 - 51.

[12] Morris, M., Risopoulos, J. and Beck, D. (1999). Genetic Change in FarmerRecycled Maize Seed: A Review of the Evidence". International Maize and Wheat Improvement Center Economics Working 99-07.

[13] Reeves, T.G. and Cassaday, K. (2002). History and past achievements of plant breeding. Australian Journalof Agricultural Research 53: 851-863.

[14] Simtowe, F., Mduma, J., Phiri, A., Thomas, A. and Zeller, M. (2007). Can Risk- aversion Towards Fertilizer Explain part of the Non-adoption Puzzle for Hybrid Maize? Empirical Evidence from Malawi. Journal of Applied Sciences 6(7): 1490 1498.

[15] URT (2013). National Agricultural Policy.Dar es Salaam: Ministry of Agriculture Food Security and Cooperatives. $50 \mathrm{pp}$.

[16] USAID (2010). Staple Foods Value Chain Analysis. Country report Tanzania. USAID

[17] Willock, J., Deary, I., Edwards-Jones, G., Gibson, G., McGregor, M., Sutherland, A., Dent, J., Morgan, O. and Grieve, R. (1999). The role of attitudes and objectives in farmer decision making: business and environmentally-oriented behaviour in Scotland. Journal of Agricultural Economics 50(2): 286-303. 